\title{
A Systematic Approach towards the Identification and Protection of Vulnerable Marine Ecosystems
}

Jeff A. Ardron*a Malcolm R. Clark ${ }^{b}$, Andrew J. Penney ${ }^{c}$, Thomas F. Hourigan ${ }^{d}$, Ashley A. Rowden ${ }^{b}$, Piers K. Dunstan $^{\mathrm{e}}$, Les E. Watling ${ }^{\mathrm{f}}$, Timothy M. Shank ${ }^{\mathrm{g}}$, Di M. Tracey ${ }^{\mathrm{b}}$, Mathew R. Dunn ${ }^{\mathrm{h}}$, Steven J. Parker ${ }^{\mathrm{b}}$

${ }^{*}$ Corresponding author: jeff.ardron@iass-potsdam.de, +49 15735234960

a Institute for Advanced Studies in Sustainability, Berliner Str. 130, 14467 Potsdam, Germany; formerly, Marine Conservation Institute, 122 C Street NW, Washington DC, 20001, USA

${ }^{\mathrm{b}}$ National Institute of Water \& Atmospheric Research, 301 Evans Bay Parade, Wellington 6021, New Zealand

${ }^{\mathrm{C}}$ Australian Bureau of Agricultural and Resource Economics and Sciences, 18 Marcus Clarke Street, Canberra, ACT 2601; formerly, Ministry of Fisheries, Wellington, New Zealand

${ }^{d}$ U.S. National Oceanic and Atmospheric Administration, Fisheries Service, Office of Habitat Conservation, 1315 East-West Highway, Silver Spring, MD 20910, USA

${ }^{\text {e}} \mathrm{CSIRO}$ Marine and Atmospheric Research, GPO Box 1538 Hobart, Tasmania 7001, Australia

${ }^{\mathrm{f}}$ University of Hawaii at Manoa, Honolulu, HI 96822, USA

${ }^{\mathrm{g}}$ Woods Hole Oceanographic Institution, Woods Hole, MA, USA

${ }^{\mathrm{h}}$ Victoria University of Wellington, Wellington, New Zealand; formerly, National Institute of Water \& Atmospheric Research, Wellington, New Zealand

Email addresses of all authors: jeff.ardron@iass-potsdam.de; Malcolm.Clark@niwa.co.nz; Andrew.Penney@daff.gov.au; Tom.Hourigan@noaa.gov; Ashley.Rowden@niwa.co.nz; piers.dunstan@csiro.au; watling@hawaii.edu; Di.Tracey@niwa.co.nz; tshank@whoi.edu; Matthew.Dunn@vuw.ac.nz; Steve.Parker@niwa.co.nz 


\title{
A Systematic Approach towards the Identification and Protection of Vulnerable Marine Ecosystems
}

\begin{abstract}
The United Nations General Assembly in 2006 and 2009 adopted resolutions that call for the identification and protection of vulnerable marine ecosystems (VMEs) from significant adverse impacts of bottom fishing. While general criteria have been produced, there are no guidelines or protocols that elaborate on the process from initial identification through to the protection of VMEs. Here, based upon an expert review of existing practices, a 10-step framework is proposed: 1) Comparatively assess potential VME indicator taxa and habitats in a region; 2) determine VME thresholds; 3 ) consider areas already known for their ecological importance; 4) compile information on the distributions of likely VME taxa and habitats, as well as related environmental data; 5) develop predictive distribution models for VME indicator taxa and habitats; 6) compile known or likely fishing impacts; 7) produce a predicted VME naturalness distribution (areas of low cumulative impacts); 8) identify areas of higher value to user groups; 9) conduct management strategy evaluations to produce trade-off scenarios; 10) review and reiterate, until spatial management scenarios are developed that fulfil international obligations and regional conservation and management objectives. To date, regional progress has been piecemeal and incremental. The proposed 10-step framework combines these various experiences into a systematic approach.
\end{abstract}

Highlights

- The United Nations has passed resolutions to protect vulnerable marine ecosystems (VMEs);

- Limited practical guidance exists on how to identify VMEs;

- Approaches differ regionally, but none to date have been systematic;

- Experiences and good practices are compiled here into a 10-step systematic approach;

- Better integration across sectors will become increasingly necessary.

Keywords

High seas; vulnerable marine ecosystems; systematic conservation planning; ABNJ; VME; RFMO 


\section{Introduction}

\subsection{United Nations bottom fishing resolutions}

A large number of commercial fisheries throughout the world ocean target fish species that live close to the seafloor. These demersal fisheries often use bottom trawl gear, which has the ability to capture large volumes of fish and other taxa. While all bottom-contact fishing gear can harm fragile seafloor habitats, bottom trawls are widely recognised to cause extensive damage, especially in areas where benthic invertebrate species such as corals and sponges form fragile biogenic structures $[1,2,3,4,5,6,7]$.

In seeking to protect vulnerable marine ecosystems (VMEs) from significant adverse impacts of bottom fishing, the United Nations General Assembly (UNGA) adopted in 2006 Resolution 61/105 [8]. It applies to fisheries in areas beyond national jurisdiction (ABNJ), which make up about $64 \%$ of the global ocean. Subsequent reviews by the UN in 2009 and 2011 identified progress and challenges in the implementation of the resolution. As a result, the UNGA adopted Resolutions 64/72 [9] and 66/68 [10], emphasising need for full implementation "on an urgent basis." Resolution 66/68 also invited the Food and Agriculture Organization of the United Nations (FAO) to facilitate implementation of the Deep Sea Fisheries guidelines, inter alia, by developing guidance on the application of criteria for identifying VMEs.

To date, the identification of VMEs has been conducted by regional fisheries management organisations / agreements (RFMO/As), with different approaches being developed in each region. This has allowed for regional and institutional characteristics and provided opportunities to evaluate the success or failure of different approaches. However, differences in approach have also resulted in varying effectiveness in protecting VMEs [11]. Resolution 64/72 called upon States and RFMO/As to enhance efforts to cooperate to collect and exchange scientific and technical data and information by "exchanging best practices" and "promoting consistent implementation of best practices across fisheries and regions" [9].

\subsection{VME identification criteria}

In 2009, the FAO published International Guidelines for the Management of Deep-Sea Fisheries in the High Seas, in order to assist States and RFMO/As in implementing the UNGA Resolution 61/105 [12]. It recommends that five biological characteristics should be used as criteria in the identification of VMEs. In the same year, the Commission for the Conservation of Antarctic Marine Living Resources (CCAMLR) held a workshop on VMEs at which it agreed to evaluate Antarctic benthic taxa using seven criteria, similar to those developed by FAO, with additional consideration of motility and larval dispersal [13].

The Convention on Biological Diversity (CBD) developed seven criteria in 2008 for identifying Ecologically or Biologically Significant Areas (EBSAs) in open-ocean waters and deep sea habitats, which may also be relevant to the identification of VMEs [14]. The objectives behind EBSAs differ from the fisheries management-oriented ones of FAO, and they use somewhat different terminology. However, expert reviews by the CBD and FAO have concluded that similar data can be used for both VME and EBSA criteria, and that the two approaches complement one another [15, 16].

Comparisons of the FAO, CCAMLR, and CBD criteria are provided in Table 1. 
Table 1. Comparison of FAO VME, CCAMLR VME, and CBD EBSA criteria. Sources: FAO International Guidelines for the Management of Deep-Sea Fisheries in the High Seas [12]; CCAMLR workshop on vulnerable marine ecosystems [13]; CBD Decision IX/20 Annex 1 [14]. For full definitions, rationale, illustrations, and explanations, see source documents. The criteria have been re-ordered for comparison.

\begin{tabular}{|c|c|c|c|c|c|}
\hline \multirow{2}{*}{\multicolumn{2}{|c|}{$\begin{array}{l}\text { FAO VME } \\
\text { Definition (excerpted) }\end{array}$}} & \multicolumn{2}{|r|}{ CCAMLR VME } & \multicolumn{2}{|r|}{ CBD EBSA } \\
\hline & & Criterion & Definition (excerpted) & Criterion & Definition (excerpted) \\
\hline $\begin{array}{l}\text { Uniqueness or } \\
\text { rarity }\end{array}$ & $\begin{array}{l}\text { An area or ecosystem that is unique or that } \\
\text { contains rare species whose loss could not be } \\
\text { compensated for by similar areas or ecosystems. } \\
\text { These include: } \\
\text { - habitats that contain endemic species; } \\
\text { - habitats of rare, threatened or endangered } \\
\text { species that occur only in discrete areas; or } \\
\text { - nurseries or discrete feeding, breeding, or } \\
\text { spawning areas. }\end{array}$ & $\begin{array}{l}\text { Rare or unique } \\
\text { populations }\end{array}$ & $\begin{array}{l}\text { Species that create dense, isolated } \\
\text { populations. }\end{array}$ & Uniqueness or Rarity & $\begin{array}{l}\text { Contains either (i) unique, rare } \\
\text { (occurs only in few locations) or } \\
\text { endemic species, populations or } \\
\text { communities, and/or (ii) unique, } \\
\text { rare or distinct, habitats or } \\
\text { ecosystems; and/or (iii) unique or } \\
\text { unusual geomorphological or } \\
\text { oceanographic features. }\end{array}$ \\
\hline $\begin{array}{l}\text { Functional } \\
\text { significance of } \\
\text { the habitat }\end{array}$ & $\begin{array}{l}\text { Discrete areas or habitats that are necessary for } \\
\text { the survival, function, spawning/reproduction or } \\
\text { recovery of fish stocks, particular life-history } \\
\text { stages (e.g. nursery grounds or rearing areas), or } \\
\text { of rare, threatened or endangered marine } \\
\text { species. }\end{array}$ & Habitat-forming & $\begin{array}{l}\text { The degree to which they create habitat } \\
\text { that could be used by other organisms. }\end{array}$ & $\begin{array}{l}\text { Special importance for } \\
\text { life history stages of } \\
\text { species } \\
\text { Importance for } \\
\text { threatened, endangered } \\
\text { or declining species } \\
\text { and/or habitats }\end{array}$ & $\begin{array}{l}\text { Areas that are required for a } \\
\text { population to survive and thrive. } \\
\text { Area containing habitat for the } \\
\text { survival and recovery of } \\
\text { endangered, threatened, } \\
\text { declining species or area with } \\
\text { significant assemblages of such } \\
\text { species. }\end{array}$ \\
\hline Fragility & $\begin{array}{l}\text { An ecosystem that is highly susceptible to } \\
\text { degradation by anthropogenic activities. }\end{array}$ & Fragility & $\begin{array}{l}\text { The potential for damage or mortality } \\
\text { resulting from physical disturbance from } \\
\text { bottom fishing gear. }\end{array}$ & $\begin{array}{l}\text { Vulnerability, Fragility, } \\
\text { Sensitivity, or Slow } \\
\text { recovery }\end{array}$ & $\begin{array}{l}\text { Contain a relatively high } \\
\text { proportion of habitats, biotopes } \\
\text { or species that are highly } \\
\text { susceptible to degradation or } \\
\text { depletion by human activity or by } \\
\text { natural events. }\end{array}$ \\
\hline \multirow{4}{*}{$\begin{array}{l}\text { Life-history } \\
\text { traits of } \\
\text { component } \\
\text { species that } \\
\text { make recovery } \\
\text { difficult }\end{array}$} & \multirow{4}{*}{$\begin{array}{l}\text { Ecosystems that are characterized by } \\
\text { populations or assemblages of species with one } \\
\text { or more of the following characteristics: } \\
\text { - slow growth rates; } \\
\text { - late age of maturity; } \\
\text { - low or unpredictable recruitment; or } \\
\text { long-lived. }\end{array}$} & Slow growth & $\begin{array}{l}\text { Organisms which grow slowly will take a } \\
\text { longer time to attain a large size or } \\
\text { reproductive maturity. }\end{array}$ & \multirow[t]{4}{*}{$\begin{array}{l}\text { Vulnerability, Fragility, } \\
\text { Sensitivity, or Slow } \\
\text { recovery }\end{array}$} & \multirow[t]{4}{*}{ Slow recovery. } \\
\hline & & $\begin{array}{l}\text { Larval dispersal } \\
\text { potential }\end{array}$ & $\begin{array}{l}\text { [Limited dispersal] influences the ability of } \\
\text { a species to recolonise impacted areas. }\end{array}$ & & \\
\hline & & Longevity & $\begin{array}{l}\text { Estimate of maximum longevity for the } \\
\text { members of the taxon }\end{array}$ & & \\
\hline & & $\begin{array}{l}\text { Lack of adult } \\
\text { motility }\end{array}$ & $\begin{array}{l}\text { Lack of motility [adds] some degree of } \\
\text { vulnerability and decreases resilience } \\
\text { because as adults those organisms } \\
\text { cannot redistribute themselves in }\end{array}$ & & \\
\hline
\end{tabular}




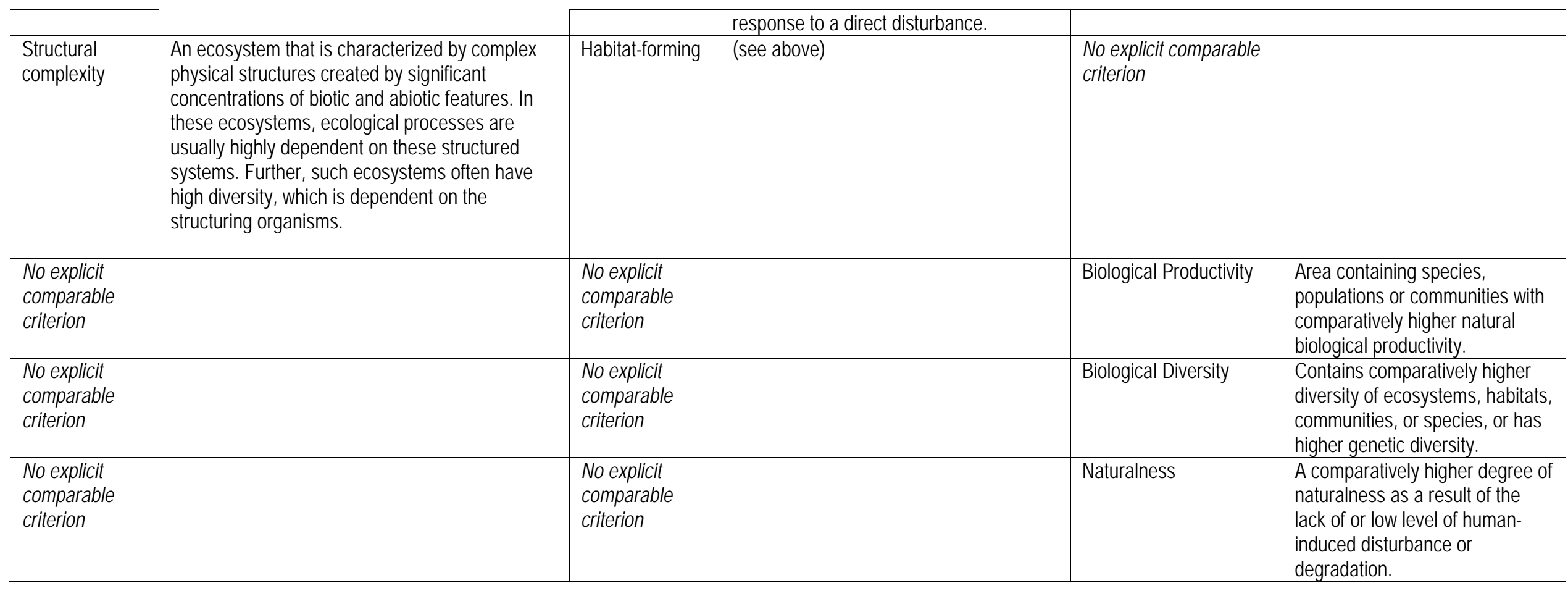




\section{Methods}

In December 2011, a group of fifteen scientists and managers with experience and expertise in high seas fisheries and deep-sea ecosystems met to discuss "Science requirements for effective governance of bottom fisheries in areas beyond national jurisdiction". Participants of this workshop shared their experiences in implementation of UNGA Resolutions through RFMO/As in the Northwest Atlantic, Northeast Atlantic, the South Pacific and the Antarctic. Merging successful elements from the various regional approaches with the latest scientific thinking, the participants sought to develop an overarching, systematic, consistent, and transparent approach for the identification of VMEs that would be relevant in all regions. Post-workshop discussions resulted in refinement of the 10-step process for the identification and protection of VMEs.

\section{Results and Discussion}

\subsection{Step 1: Comparatively assess potential VME indicator taxa and habitats in a region}

The FAO criteria for identifying VMEs, discussed above, form a useful starting point. However, they may need to be elaborated to be relevant to the specific taxa, habitats and fisheries in a given region. Better studied taxa and habitats can provide benchmarks to assist with relative rankings for those less-studied.

For example, for each of the criteria developed for the Antarctic, benthic taxa were evaluated in terms of susceptibility to lasting damage from bottom fishing. Where estimates of maximum longevity for a taxon were available, they were ranked as Low ( $<10$ years), Medium ( $10-30$ years) and High ( $>30$ years). CCAMLR identified 23 taxa for which at least one of the seven criteria was rated as "high" [13] and then ranked these in terms of likelihood of longline fishery interactions

Some species or habitats are more vulnerable than others and it is difficult to define exactly when an assemblage of organisms in an ecosystem should be considered a VME. Achieving a high ranking for one criterion, however, should be sufficient for it to be considered as a potential VME indicator. Tabulating relative measures across multiple criteria (and potentially different gear types) can provide combined scores that provide an indication of where a particular indicator species or habitat lies on the continuum from hardy and resilient through to fragile and vulnerable.

For the Northwest Atlantic, over 500 benthic invertebrate megafaunal taxa caught in research vessel surveys were classified initially into broad taxonomic groupings and considered by experts against the life history and functional significance criteria drawn from the FAO Guidelines. In order to establish functional significance, it was the dense aggregations (beds/fields) that were assumed by the Northwest Atlantic Fisheries Organisation (NAFO) Scientific Committee to be VMEs. In addition to the coral and sponge taxa that had previously been addressed, three additional groups emerged as potential indicators of VMEs: crinoids, erect bryozoans and large sea squirts [17].

While a scientific process should clarify where species and habitats lie along the VME indicator continuum, decisions regarding the cut-off would need to be informed by the constitution and values of each RFMO/A. Corals and sponges are usually the first to be identified as VME indicators [18, 19], but there are many other taxa, including mobile taxa such as fishes and elasmobranchs that could potentially qualify under the FAO criteria. Many deep-sea species have not been well studied and assessments of vulnerability may have to be informed by expert judgement. 
When VME criteria have been systematically applied, the practice has been to apply equal weighting to all criteria and add them together [13]. However, different criteria may need to be weighted differently. Adding relative scores together can be inappropriate when the values are statistically independent. The criteria "rarity" and "habitat-forming", for example, are probably independent. With orthogonal values, using the square root of the sum of squares avoids the problem of five 1's (on a scale of 1 to 5) adding up to a high value score of 5 . The total of five 1's for the square-root of summed squares would instead be 2.2 (i.e., medium-low). On the other hand, "longevity" and "slow growth" are correlated criteria and could be averaged into a single combined life history value.

\subsection{Step 2: Determine VME thresholds}

Ideally, VMEs would be identified by fishery-independent means (e.g., direct observations) that quantify the density or aggregation of the VME indicator species, the extent of the associated habitat, and the damage caused by particular fishing gears. In most cases, however, the only information available comes from VME indicator taxa that are landed on deck as bycatch in the course of fishing. Since trawl nets or longlines are poor sampling tools for most sessile benthic organisms, landed bycatch of VME indicator taxa is an imperfect indication of the benthic community [20]. Nevertheless, bycatch is often the only means by which to identify when a VME has been encountered during fishing, and to determine thresholds that will trigger management actions.

The setting of thresholds requires translating what lands on deck as bycatch into a predicted level of density or aggregation of the species on the seafloor and the expected extent of the associated habitat. From there, a decision has to be made on what would constitute a significant adverse impact. Given the many uncertainties, the systematic development, testing, and revision of threshold values is necessary. Threshold weights (or volumes) should not just be set for the entire bycatch, but also should be considered by taxonomic group. For example, New Zealand vessels operating in the South Pacific Regional Fisheries Management Organization (SPRFMO) area have separate weight thresholds for a number of different taxa, and also apply a component of their VME encounter scoring system based on whether a catch contains three or more VME taxa (e.g., stony corals + sponges + seastars), even though bycatch weights of each individual component may not meet individual weight thresholds. This approach allows management action to be informed by overall VME indicator bycatch, in addition to landings of individual indicator taxa [21]. If the VME indicator taxa have widely differing weights and individual threshold values, triggers can be set at different weights for different taxa, or can be normalised (e.g. to a scale of 1-10) before being added together. If more than one gear type is used, thresholds should be adjusted for each type [20].

For the New Zealand VME evidence protocol [22] and in initial Northwest Atlantic analyses, threshold values of VMEs were analysed based on patterns in the cumulative catch curves such that a point of maximum curvature or rapid change toward the asymptote may indicate a naturally occurring or ecologically relevant reference point [23].

Adaptive management is necessary for finding an operationally meaningful threshold value. The VME encounter protocol can be made more responsive by including more than just the areas of high theoretical bycatch. In the Northwest Atlantic, for example, the current encounter threshold for sponge bycatch $(300 \mathrm{~kg}$ ) is rarely met [24]. In the Northeast Atlantic, where there is not an observer programme, no encounters above the coral-sponge thresholds have ever been reported [25].

3.3 Step 3: Consider areas already known for their ecological importance 
While much of the deep sea is poorly known, there are some places recognised by researchers and/or fishers that stand out for ecological reasons. These may be specific sites (such as a particular bank or seamount), or areas made special by a confluence of environmental conditions producing, for example, unusually high levels of biodiversity or productivity. Because these areas often have more research and information, they can offer "low hanging fruit" in the VME identification process. They may have been already identified by previous processes such as the CBD's regional EBSA workshops (see Dunn et al this issue). Well studied features within the exclusive economic zone (EEZ) of States can also inform the identification of comparable sites in ABNJ.

Possible examples could include: 1) shallower than normal seamounts or plateaux (with a shallow photic ecology) [26]; 2) larger complexes of high relief topography; 3) physical features such as canyons that converge oceanic currents and upwelling into spatially constrained areas of increased productivity [27]; and 4) hydrothermal vent or cold methane seep sites and associated chemosynthetic communities - the latter of these are specifically mentioned in the list of potential VME taxa appended to the FAO DeepSea Guidelines [12].

VME identification is an iterative process. These well-known places, if they qualify as VMEs, should represent the first iteration resulting in early management action. Similarly, EBSAs already identified though the CBD process should be promptly assessed by RFMO/As for their applicability as VMEs.

3.4 Step 4: Compile information on the distributions of likely VME indicator species and habitats, with related environmental data

Some data for VME indicator taxa are available in global databases such as Ocean Biodiversity Information System (OBIS) [28], Global Biodiversity Information Faculty (GBIF) [29], Global Procellariiform Tracking Database [30], etc., as well as regional databases maintained by science institutes or management agencies. These databases typically hold records of species presence, although additional information may be available on density or abundance of certain taxa and the areal extent of habitats (see Step 5). Data should be provided at the highest possible spatial resolution. In data-poor situations, a systematic and precautionary approach, such as outlined in Heupel and Auster (2013), should be taken [31].

Additional sampling will always improve the accuracy of estimates and models to help understand the potential impact of fishing and other anthropogenic effects on VME habitat. Observers on fishing vessels are in a unique situation to sample VME fauna from a wide spatial area and from targeted fisheries effort. This information can be combined with specific baseline research data on VMEs to provide a greater understanding on the presence, spatial distribution, and variability of occurrence of VMEs, as well as help define areas of refugia. In turn this can help inform ecosystem-based management decisions and indicate protection of these benthic habitats from manageable anthropogenic impacts [32]. Given that benthic communities are patchy in their distribution and abundance, observer coverage needs to be high. For example, the SPRFMO Data Standards require $100 \%$ observer coverage of bottom trawling operations in the SPRFMO Area. RFMO/As where (independent) observer programs are not in place are at a considerable disadvantage when attempting to delineate VMEs.

Taxonomic guides, such as those developed by NAFO [33], CCAMLR [34] and SPRFMO [35] are essential for the reliable identification of bycatch by observers. Species within groups such as hydroids, primnoid corals, stylasterid hydrocorals, certain sponge taxa and snake stars can be confused and difficult to identify [36, 37, 38], and when uncertain, samples should be kept for later identification. Observers should record all benthic bycatch brought up by a fishing operation. For the North Atlantic (NAFO and 
the North East Atlantic Fisheries Commission -NEAFC), VME indicators are considered by habitat type and/or at the taxonomic level of family rather than by all likely species that could be indicators of VMEs [39].

In some cases, industry has independently gathered data which could be combined with observer data to assist with VME identification. Independent underwater surveys, despite their expense in the deep sea, are needed to inform and ground-truth less expensive approaches such as observers and predictive habitat modelling (discussed below).

\subsection{Step 5: Develop predictive distribution models for VME indicator taxa and habitats}

The location of deep-sea VMEs is generally poorly known, and hence other approaches beyond Step 3 need to be taken to predict the likelihood of VME occurrence in large unexplored areas.

Predictive modelling is a useful tool for extrapolating species distribution based on known environmental conditions under which species occur. Results from the latest global predictive coldwater coral modelling are at a $1 \mathrm{~km} \times 1 \mathrm{~km}$ resolution, which is sufficient for most management decisions [40]. Modelling can be complemented by using biogeographic classifications to guide the stratification of sub-regions, to ensure that intact examples of VMEs are protected in each biogeographic sub-region or "province" [41]. That said, biogeographic classifications are broad in scale and can miss important features that may be unique to an area [42]. The small size of some habitats (e.g., seamounts) in comparison with the spatial resolution of many of the available environmental data sets, requires regional analyses to fill in such gaps [43, 44], tailored for each RFMO/A's area of competence, and at the finest possible resolution [45].The results of existing habitat prediction models can be used to start developing spatial VME-likelihood layers to inform management discussions, even if they do not cover an entire management region [46].

Most habitat suitability modelling to date has focussed on presence rather than abundance of VME indicator species. However, most areas designated as VMEs have been assessed based on their density as well as biodiversity. Therefore, models should aim to predict areas of high abundance and high biodiversity. The taxonomic data needed to support these models are typically not collected during fishing operations, as they require known selectivity for various taxa (such as video or photomosaic surveys). Knowledge of areas of where VME indicators do not occur (absences) is also beneficial, to constrain models to the factors that are useful in predicting presence and abundance.

Predictive habitat models come with many caveats. In modelling there are two general types of error, each with their own considerations. False negatives are of concern to conservation because those areas that have VMEs that do not show up in the model would very likely be open to fishing and hence put at risk. If sampling is not well distributed by biogeographic region or depth (often the case on the high seas), models are likely to yield false negatives. Therefore, even with the very best models in place, there is still a need to develop protocols (e.g., 'move-on rules') for a response to protect VME indicator taxa unexpectedly encountered during fishing operations.

False positives are usually the more common type of error, whereby more area is predicted to contain a VME than actually exist. This over-prediction can result from model reliance on moderate resolution physical and environmental data, from 'presence-only' modelling approaches and from grouping species with different distributions into higher taxonomic groups - all characteristics of most high seas habitat modelling efforts to date. This means that fishing could be excluded from some areas even though the predicted VME is not actually there. Key in interpreting the risk of such over-prediction is the 
quantification of estimates of prediction uncertainty. For presence-absence data, the respective consequences of each type of error (omissions, commissions) can be considered when choosing a threshold, or by using different thresholds for different decisions [47]. However, without additional biological and physical data containing both presence and absences, it is very difficult to increase prediction accuracy and reduce prediction uncertainty. Management decisions should be made with caution in areas with high prediction uncertainty.

All modelling still requires validation. This can partly be achieved by setting aside some data points (cross validation) but field validation (i.e. ship based surveys) is the best way to test and improve the predictive power of these models. The steady addition of fisheries observer and direct survey data should improve model performance over time.

\subsection{Step 6: Compile known or likely fishing impacts}

Several human activities, including bottom-contact fishing, have negative impacts on deep-sea ecosystems. As a result, not all deep-sea areas are pristine, and places that once contained VME species and habitats may now have far fewer. In addition, not all areas are of equal value to the fishing industry, with more accessible areas (shallower and closer to port) generally being more highly valued than less accessible places. Because many deep-sea fish stocks have suffered declines, areas of previous economic value may no longer be valuable to industry. Hence, there are three fisheries considerations to take into account: 1) the spatial distribution and intensity of historical fishing effort; 2 ) the expected effects of different gear types on different (predicted) VMEs, and; 3 ) areas that are currently of higher value to the fishing industry, usually because they still support economically valuable fish stocks. In this section, the first of these considerations is discussed. The second consideration should be part of the VME assessment in steps 1 (3.1) \& 2 (3.2) above, and will come into play in the next Step 7 (3.7) below. The third consideration is covered in Step 8 (3.8), below.

As an interim measure to protect undamaged VMEs, some RFMO/As have attempted to quantify and map previous fishing effort and "freeze the footprint" (i.e. restrict fishing to previously fished areas). The efficacy of this approach varies, depending on the availability and reliability of fishing data. Fishing may have occurred in an area but never have been reported, or spurious data can give the false impression that fishing has occurred in far off places where it has not. Historical data gathered before Global Positioning System (GPS) are often inaccurate, and tows may not have been conducted where historical records indicate they were. Some level of historical fishing effort was probably not recorded at all [48]. Some RFMO/As have taken an approach of using large grid squares (e.g. 20 minute by 20 minute blocks), whereby any cell that has a trawl track (or some minimum number of trawl tracks) within it is considered to be part of the fishing footprint, and hence remains open to some level of fishing. This approach has the shortcoming that not all of the area within the large blocks may have actually been trawled, and much of the area within it could be relatively pristine.

Usually the reason given as to why fishing data have been aggregated into large blocks is that the VME and/or logbook data are seen to be proprietary. This typically results in objections to fishing footprints being expressed at finer resolution, as this may indicate the position of important fishing areas. Despite occurring in areas beyond national jurisdiction (i.e. a global commons), perceptions of the proprietary nature of detailed flag state fishing data have often impeded analyses at an operationally meaningful scale. Expert groups have strongly criticised the blunt approach that such data restrictions have created [49]. The authors of this paper share the concern that poor management recommendations can arise from using large spatial blocks as the basis for assessment and management. 
By "freezing the footprint", there is a perverse incentive to withhold information, since providing more information could lead to further closures. If there were an attempt to "freeze the VMEs" (i.e. close fishing blocks where VMEs have been detected) then industry would be incentivised to share information that would lead to the re-opening of areas.

Objectively designed spatial closures remain preferable to any footprint-freezing approach. Because the fishing effort within the footprint can vary greatly, presence / absence fishing data are limited in their usefulness; full resolution fishery data are necessary to determine the relative impacts. Data should be carefully scrutinised and corrected to remove position reporting errors that could result in the incorrect incorporation of unfished areas. The spatial density of historical fishing effort can then be calculated (e.g. using GIS kernel density function, merged, buffered swept-areas or other analytical methods $[50,51])$ so that the relative (risks of) impacts in different areas can be estimated. Relative impact measures should be scaled appropriately to the gear types. The combined total provides an estimate of the relative impacts across the region, and hence also the relative naturalness of those places remaining [52].

If other human impacts (e.g., seabed mining or oil and gas exploration) have occurred or are planned, these should also be taken into consideration.

\subsection{Step 7: Produce a predicted VME naturalness distribution (areas of low cumulative impacts)}

Some places predicted to contain VMEs have already been impacted by heavy concentrations of fishing. Hence VMEs would no longer exist in their original numbers, integrity or biodiversity, and in many cases would take many years to recover. The UNGA resolutions are silent on the question of VME recovery, and hence it is left to the discretion of the management organisations and States whether the recovery potential of a given site outweighs the benefits to fishing, or not. Predictive habitat models, and historical species records, do not take these sorts of extrinsic stressors into account. In order to get a more accurate picture of the current state of affairs, the predictive habitat models for VMEs (Step 5) should be combined with human impacts information developed in Step 6.

Combining the two layers is the topic of recent work in New Zealand's waters, which could also be applied in ABNJ [53]. In order to predict site-specific VME intactness, the analysis relied on tow-by-tow resolution (underlining the necessity of not aggregating such data). 'Discounting' factors, calibrated to survey data, were then applied to previously fished areas, quantitatively assessing the reduction in VMElikelihood resulting from varying levels of historical fishing effort.

A similar method was developed to evaluate the risk from seamount fisheries on stony coral distribution, with seamounts that were known to have had more than a certain level of effort (or amount of catch), being assumed to have been highly impacted, and hence were removed from the analysis [54]. This filtering focussed attention on the remaining combined layer of predicted VMEs and human impacts to maximize the protection of those places that are still most intact but fall within fishing depths and are still at risk. If fishing appears to have already affected most of a VME's distribution, then some of those areas should be set aside and monitored for recovery. Even within heavily fished areas, there could be remnants of VMEs that do not exist elsewhere. Such areas would be prime candidates for focussed seabed biodiversity surveys to determine residual VME presence.

3.8 Step 8: Identify areas of higher value to user groups 
With all the above steps completed, recommendations can be made for places that should be protected, based on being ecologically important or unique places, where VMEs are most intact ("natural"), and where they are most at risk.

Closing areas containing VMEs to bottom-contact fishing gears is generally acknowledged to be the most effective protection method and would fully meet the requirements of the UNGA Resolutions to prevent significant adverse impacts to VMEs. In practice, the selection of closures is usually an iterative process, typically taking into consideration the opinions on alternative options from the fishing industry and the wider stakeholder community.

Often, stakeholder involvement occurs rather late in the process after a suite of proposed closed areas has been put forward. However, prior integration of stakeholder values directly into the analysis can produce more efficient scenarios for discussion and revision, and reduce time wasted on generation of protection scenarios that are broadly unacceptable to user groups. While the UNGA Resolutions do not address prioritising potential VME areas based on stakeholder values, in practice it is inevitable that, where alternative proposals have similar merits based on scientific analyses, stakeholder values could tip the scale one way or the other. An example of such a participatory process is provided by spatial closure proposals for the Ross Sea Region under CCAMLR [55], which is not just about VME protection, but marine protected areas more generally.

Maps of spatial distribution of historical effort or catch (Step 6) provide useful indicators of areas of value to the fishing industry. However, not all places that were valuable to fishers in the past are necessarily so now. The fisheries literature is testament to changes in fish distribution with heavy fishing pressure, whether occurring over centuries of exploitation; e.g., ling in the North Sea and Skagerrak [56], or cod on the Grand Banks [57], or fisheries such as orange roughy that declined over just a few decades [58]. Regional climate variability and climate change can also play a role in changing the distribution and productivity of fish species and should be incorporated into decisions [59]. Nevertheless, fishing grounds that were important in the past are still often considered important by fishermen, as it is often hoped they may in the future be productive again [60].

Sorting out what is, or is no longer, valuable is particularly useful when performing a multiple criteria analysis (Step 9, below), and could help to generate support for measures to allow for the recovery of damaged areas. The intent of the UNGA Resolutions is to protect VMEs wherever they occur, including in areas currently being fished. Given the very slow recovery rates of fragile deep-sea ecosystems, areas known or likely to contain VMEs, and which are afforded protection as a result of the processes described in this paper, should not later be re-opened because open areas have been over-exploited and have lost their fisheries value. The likelihood that fisheries will expand into new (or lightly fished) areas, especially if traditional fishing areas become depleted, is another reason why efforts to protect VMEs should not be delayed.

\subsection{Step 9: Conduct management strategy evaluations to produce trade-off scenarios}

If the above steps are followed, a region will have several spatial information layers to be considered: already known ecologically important places; VME indicator taxa, each with predicted distributions that take into account naturalness; and user-group valued places. There may be additional criteria, such as the potential genetic connectivity among different sites that may affect recruitment or recovery from damage. Sorting out how to most efficiently select candidate closures and other spatial protections amongst these layers will often then require evaluation of multiple criteria, review and re-iteration (Step 10). 
At one end of the scale, some VMEs will exhibit extremely high ecological value, strongly suggesting that there should be no bottom fishing. At the other end of the scale will be sites that have no known or predicted VMEs. In between is a continuum of potential VME sites where decision-making can benefit from systematic guidance on the trade-offs amongst multiple value criteria.

There are a variety of systematic approaches possible for choosing candidate sets of sites, all of which rely on combining, and accounting for, multiple criteria. Some methods are more robust and reliable than others [61]. For combining criteria, the approach first used is often some sort of additive scoring system. However, combining scores (through addition or otherwise) brings with it several limitations [62]. For example, for each of the VME distributions, a relative score will be assigned. However, it is broadly accepted that protecting many weak features is not as valuable as protecting one excellent example and so, as discussed above in 3.2 , adding values of different criteria together can produce misleading results.

GIS offers the opportunity to quickly map multiple layers that illustrate the distribution of ecologically significant places and/or VME indicator taxa. It is tempting to conclude that the areas of highest overlap are the most valuable. Indeed, some areas of overlap can represent good choices, particularly if spatially correlated about a fixed or recurrent feature (e.g. a seamount or upwelling). However, relying on overlapping GIS layers to identify high value VME areas means that core areas of many non-correlated VMEs can be missed. Overlapping regions may also be too small and fragmented to viably support the VMEs in question. Hence, while mapping features is valuable for visualisations and can point out opportunistic convergences, relying solely on the density of overlapping layers is insufficient to comprehensively protect VMEs.

Manually sorting through more than five or six GIS layers, each with different naturalness and VME values and associated conservation targets, quickly gets complicated and beyond the realm of intuition. A more systematic approach uses optimisation software tools. Multiple criteria site selection tools (e.g., Marxan [63], Zonation [64], ConsNet [65]) can address network-level solutions, producing several spatially efficient options. The use of numerical optimization tools can be used to propose options, break deadlocks in negotiations, and seek mutually beneficial alternative solutions [66]. However, the caveats around data and predictive modelling still apply.

Some users distrust software tools as "black boxes". Another approach with similarities to the steps advocated in this paper, without the use of optimisation software, has been explored for the New Zealand bottom trawl footprint in the SPRFMO Area [51]. The relative costs (loss of catch to industry) and benefits (protection of areas with high predicted VME likelihood) of opening or closing any 20minute block in the footprint were manually compared using GIS and summary tables. In another example, New Zealand and the United States took an approach for the CCAMLR Ross Sea planning process that involved experts and stakeholders setting targets and costs, and then using GIS. After several iterations, the results were similar to those produced earlier by the optimisation tool Marxan [67].

In data-scarce situations, if predicted VME indicator taxa layers are not available / possible, it is still beneficial to use discussions with users, scientists, managers and other experts to sort through multiple criteria problems. Such discussions, though difficult, can be very successful, but a systematic and transparent approach requires that regional goals, objectives, and targets be made explicit. Gaining agreement on these core values can be very time-consuming, requiring skilful facilitation. 


\subsection{Step 10: Review and re-iterate}

Spatial management is seen as the most feasible option for most offshore deep-sea fisheries management [68]. However, there will always be practical considerations, and non-spatial information that cannot be included in analyses. Revised layers, taking such input into consideration, perhaps with places "locked in" or "out", can then be re-run to see how the results are affected.

Experts and stakeholders should check the options resulting from the above processes to ensure they make sense, and to discuss alterations and variations with regulators that might better incorporate their preferences and views. Active involvement of stakeholders can be a critical factor in ensuring legitimacy and subsequent compliance. A user-intensive systematic approach requires building two-way trust with the stakeholders, which takes time and persistence for all involved [69].

The review and refinement procedure should continue until plausible scenarios are found that best fulfil international conservation obligations and regional economic and conservation objectives. Procedures should exist for new information to be incorporated into management decisions, as well as regular review of operational objectives, to ensure that identified VMEs are being adequately protected. This can only be achieved through regular monitoring, information sharing, and engagement with stakeholders and the scientific community, preferably through a dedicated review process.

\section{Conclusion}

To date, different RFMO/As have tended to take different approaches in identifying VMEs, with progress being piecemeal and incremental. The 10-step framework proposed in this paper builds upon and combines these various experiences into a systematic approach that has several clear advantages:

i. Understanding what steps should be considered beforehand should encourage more realistic expectations, preparation and budgeting;

ii. a clearly laid-out approach using broadly accepted components is more readily communicated and defensible; and,

iii. a systematic approach should lead to more objective decision making [70].

Implementation of each of the ten steps will vary according to the specific characteristics of a given fishery, its region, existing funding, scientific information, and management measures already in place. The proposed ten-step systematic approach offers a common framework by which regions can consider their progress and what next steps should be taken.

The above methods for the identification and protection of VMEs share much in common with the identification of marine protected areas (MPAs) more generally. However, unlike VMEs, it has been suggested that representative MPAs, such as committed to by the Parties of the CBD through Aichi Target 11, could in the open ocean be very large [71]. In order to make the best use of ocean space, it would be pragmatic to align the designation of VMEs and larger MPAs, to ensure that as many VMEs as possible are incorporated within planned MPA boundaries, and/or that MPAs are designed to protect VMEs. For deep sea mining, there has been a process similar to MPA network design to identify areas of particular environmental interest [72]. Similarly, the CBD has regionally been identifying EBSAs [Dunn et al this issue]. The various approaches in ABNJ strongly suggest that there is a need for better integration of marine planning efforts across sectoral authorities and international agreements. In all cases, a transparent and systematic approach, as outlined here, should be encouraged. 


\section{Acknowledgements}

The New Zealand Ministry of Science and Innovation (now known as the Ministry of Business, Innovation and Employment) provided funding for the workshop (which was one of a series of "Marine Think Tanks") and travel for US participants. The initial impetus for the Marine Think Tanks came from the Organising Committee for the International Congress for Conservation Biology. Thanks are owed to Carolyn Lundquist, Rebecca Gladstone-Gallagher, Sean Anderson, Ellie Bors, Dave Bowden, Robert Brock, Lucinda Douglass, and Alistair Dunn for helping make the workshop a success. Thanks also to Shannon Dionne for review of an early draft. The views expressed in this paper are the authors' own and do not represent those of government agencies.

\section{References}

[1] Dayton PK, Thrush SF, Agardy MT, Hofman RJ. Viewpoint: environmental effects of marine fishing. Aquatic Conservation 1995; 5:205-232.

[2] Watling L, Norse EA. Disturbance of the Seabed by Mobile Fishing Gear: A Comparison to Forest Clearcutting. Conservation Biology 1998; 12(6):1180-1197.

[3] National Research Council. Effects of trawling and dredging on seafloor habitat. 2002. National Academy Press, Washington, DC.

[4] Gage JD, Roberts JM, Hartley JP, Humphery JD. Potential impacts of deep-sea trawling on the benthic ecosystem along the northern European continental margin: a review. American Fisheries Society Symposium 2005;41:503-517.

[5] Clark MR, Koslow JA. Impacts of fisheries on seamounts. In: Seamounts: Ecology, Fisheries, and Conservation, ed. TJ Pitcher, T Morato, PJB Hart, MR Clark, N Haggan and RS Santos. Blackwell Fisheries and Aquatic Resources Series 12. 2007: pp. 413-441. Oxford, UK: Blackwell Publishing.

[6] Benn AR, Weaver PP, Billet DSM, van den Hove S, Murdock AP, et al. Human Activities on the Deep Seafloor in the North East Atlantic: An Assessment of Spatial Extent. PLoS ONE 2010; 5(9).

[7] Norse EA, Brooke S, Cheung WW, Clark MR, Ekeland I, Froese R, Gjerde KM, Haedrich RL, Hellell SS, Morato T, Morgan LE, Pauly D, Sumaila R, Watson R. Sustainability of deep-sea fisheries. Marine Policy 2012; 36(2),307-320.

[8] United Nations General Assembly. Sustainable fisheries, including through the 1995 agreement for the implementation of the provisions of the United Nations convention on the law of the sea of 10 December 1982 relating to the conservation and management of straddling fish stocks and highly migratory fish stocks, and related instruments. General Assembly Resolution 61/105, 2006; A/RES/61/105.

[9] United Nations General Assembly. Sustainable fisheries, including through the 1995 agreement for the implementation of the provisions of the United Nations convention on the law of the sea of 10 December 1982 relating to the conservation and management of straddling fish stocks and highly migratory fish stocks, and related instruments. General Assembly Resolution 64/72, 2009; A/RES/64/72.

[10] United Nations General Assembly. Sustainable fisheries, including through the 1995 agreement for the implementation of the provisions of the United Nations convention on the law of the sea of 10 December 1982 relating to the conservation and management of straddling fish stocks and highly migratory fish stocks, and related instruments. General Assembly Resolution 66/68, 2011; A/RES/66/68.

[11] Rogers AD, Gianni M. Implementation of UNGA Resolutions 61/105 and 64/72 in the Management of DeepSea Fisheries on the High Seas. DIANE Publishing, 2011.

[12] United Nations Food and Agricultural Organization. International guidelines for the management of deep-sea fisheries in the high seas. 2009. <http://www.fao.org/docrep/011/i0816t/i0816t00.htm $\geq$ [Accessed June 2013]. [13] Report of the Workshop on Vulnerable Marine Ecosystems (La Jolla, CA, USA, 3 to 7 August 2009), Annex 10 to the Report of the Twenty-Eighth meeting of the Scientific Committee, 2009.

<http://www.ccamlr.org/en/system/files/e-sc-xxviii.pdf> [Accessed June 2013]. 
[14] Convention on Biological Diversity 2008; Decision IX/20 annex 1.

$<$ http://www.cbd.int/decision/cop/default.shtml?id=11663 2 [Accessed June 2013].

[15] Convention on Biological Diversity. Expert Workshop on Scientific and Technical Guidance on the Use of Biogeographic Classification Systems and Identification of Marine Areas Beyond National Jurisdiction in Need of Protection, Ottawa, Canada. 2009; UNEP/CBD/SBSTTA/14/INF/4

[16] Food and Agricultural Organization of the United Nations. The Report of the FAO Workshop on the Implementation of the FAO International Guidelines for the Management of Deep-sea Fisheries in the High Seas Challenges and Way Forward, Busan, Republic of Korea, 10-12 May 2010. FAO Fisheries and Aquaculture Report 2011; 948.

[17] Northwest Atlantic Fisheries Organization. Scientific Council Reports 2012, published Jan. 2013. <http://archive.nafo.int/open/rb/2012/NAFO_SCRep_2012.pdf> [Accessed June 2013].

[18] Fuller SD, Murillo Perez FJ, Wareham V, Kenchington E. Vulnerable Marine Ecosystems Dominated by DeepWater Corals and Sponges in the NAFO Convention Area. Northwest Atlantic Fisheries Organization (NAFO) 2008; SCR Doc. 08/22; Serial No. N5524. <http://www.repositorio.ieo.es/eieo/bitstream/10508/769/1/SCR\%2008_22.pdf> [Accessed June 2013].

[19] Penney A, Parker S, Brown J. Protection measures implemented by New Zealand for vulnerable marine ecosystems in the South Pacific Ocean. Marine Ecology Progress Series, 2009; 397:341-354.

[20] Auster PJ, Gjerde K, Heupel E, Watling L, Grehan A, Rogers A D. Definition and detection of vulnerable marine ecosystems on the high seas: problems with the "move-on" rule. ICES Journal of Marine Science 2011; 68(2):254-

264.

[21] Penney A, Parker S, Brown J, Cryer M, Clark M, Sims B. New Zealand Implementation of the SPRFMO Interim Measures for High Seas Bottom Trawl Fisheries in the SPRFMO Area. 2008; SPRFMO-V-SWG-09.

[22] Parker S, Penney A, Clark M. Detection criteria for managing trawl impacts on vulnerable marine ecosystems in high seas fisheries of the South Pacific Ocean. Marine Ecology Progress Series, 2009; 397: 309-317.

[23] Kenchington E, Cogswell A, Lirette C, Murillo-Pérez FJ. The use of density analyses to delineate sponge grounds and other benthic VMEs from trawl survey data. NAFO SCR Doc. 09/6. 2009; serial No. N5626.

[24] Northwest Atlantic Fisheries OrganizationConservation and Enforcement Measures NAFO/FC Doc. 13/1 2013; serial No. N613. <http://archive.nafo.int/open/fc/2013/fcdoc13-01.pdf> [Accessed July 2013].

[25] International Council for the Exploration of the Sea (ICES), report of the ICES\NAFO Joint Working Group on Deep-water Ecology (WGDEC). 2013. ICES CM 2013/ACOM:28.

<http://www.ices.dk/sites/pub/Publication\%20Reports/Expert\%20Group\%20Report/acom/2013/WGDEC/wgdec_ 2013.pdf> [Accessed June 2013].

[26] Dunstan PK, Clark MR, Guinotte J, O'Hara T, Niklitschek E, Rowden AA, Schlacher T, Tsuchida S, Watling L, Williams A. Identifying Ecologically and Biologically Significant Areas on seamounts. IUCN 2011.

[27] Dunn DC (ed.), Ardron J, Ban N, Bax N, Bernal P, Bograd S, Corrigan C, Dunstan P, Game E, Gjerde K, Grantham H, Halpin PN, Harrison AL, Hazen E, Lagabrielle E, Lascelles B, Maxwell S, McKenna S, Nicol S, Norse E, Palacios D,

Reeve L, Shillinger G, Simard F, Sink K, Smith F, Spadone A, Würtz M. Ecologically or Biologically Significant Areas in the Pelagic Realm: Examples \& Guidelines - Workshop Report. IUCN 2011.

[28] <http://www.iobis.org/> [Accessed June 2013].

[29] <http://data.gbif.org/welcome.htm > [Accessed June 2012].

[30] <http://www.seabirdtracking.org/database.php $>$ [Accessed June 2013].

[31] Heupel E, Auster PJ. Eco-labeling seafood: Addressing impacts to vulnerable seafloor species, communities, habitats and ecosystems in data-poor regions. Marine Policy 2013; 38:8-15.

[32] Giman E, Passfield K, Nakamura K. Performance of regional fisheries management organizations: ecosystembased governance of bycatch and discards. Fish and Fisheries 2013; early view online: DOI: 10.1111/faf.12021, [Accessed Nov 2013].

[33] Kenchington E, Best M, Cogswell A, Maclsaac K, Murillo-Perez FJ, MacDonald B, Wareham V, Fuller SD, Jørgensbye HIØ, Sklya V, Thompson AB. Coral Identification Guide NAFO Area. Sci. Coun. Studies, 2009; 42:1-35. <http://www.nafo.int/publications/studies/coral-guide.html> [Accessed June 2013].

[34] Parker S, Tracey D, Mackay E, Mills S, Marriott P, Anderson O, Schnabel K, Bowden D, Kelly M, Lockhart S. CCAMLR VME Taxa Classification Guide. 2009. <http://www.ccamlr.org/en/system/files/VME-guide.pdf> [Accessed June 2013]. 
[35] Tracey D, Parker S, Mackay E, Anderson O, Ramm K. Classification guide for potentially vulnerable invertebrate taxa in the SPRFMO Area. 2008; SP-08-SWG-DW-03. <http://www.southpacificrfmo.org/assets/8th-MeetingNovember-2009-New-Zealand/DW-Subgroup-VIII/SP-08-SWG-DW-03-SPRFMO-VME-ID-Guide-v2-Nov-2009.pdf> [Accessed June 2013].

[36] Parker SJ, Mormede S, Tracey D, Carter M. Evaluation of VME taxa monitoring by scientific observers from New Zealand in the Ross Sea Antarctic toothfish longline fishery during the 2008-09 season. CCAMLR 2009; document WG-TASO 09/08.

[37] Tracey D, Carter M, Parker S. Evaluation of VME taxa monitoring by scientific observers. Final Research Report for Ministry of Fisheries Research Project ANT2009/01 Objective 8. 2010.

[38] Tracey D; Baird, SJ; Sanders BM; Smith MH. Distribution of protected corals in relation to fishing effort and assessment of accuracy of observer identification. NIWA Client Report 2011; no. WLG2011-33.

[39] International Council for the Exploration of the Sea (ICES), Special request, Advice June 2013.

<http://www.ices.dk/sites/pub/Publication\%20Reports/Advice/2013/Special\%20requests/NEAFC_VME_\%20indica tor_\%20species_\%20and_elements.pdf> [Accessed July 2013].

[40] Davies AJ, Guinotte JM. Global Habitat Suitability for Framework-Forming Cold-Water Corals. PLoS ONE 2011; 6(4): e18483.

[41] Clark MR, Watling L, Rowden AA, Guinotte JM, Smith CR. A global seamount classification to aid the scientific design of marine protected area networks. Journal of Ocean and Coastal Management 2011;54:19-36.

[42] Williams A, Bax NJ, Kloser R, Althaus F, Barker B, Keith G. Australia's deep-water reserve network: implications of false homogeneity for classifying abiotic surrogates of biodiversity. ICES Journal of Marine Science, 2009; 66.

[43] Tittensor DP, Baco A, Brewin P, Clark MR, Consalvey M, Hall-Spencer J, Rowden AA, Schlacher T, Stocks K, Rogers AD. Predicting global habitat suitability for stony corals on seamounts. Journal of Biogeography 2009; 36 : 1111-1128.

[44] Yesson C, Taylor M, Tittensor D, Davies A, Guinotte J, Baco-Taylor A, Black J, Hall-Spencer J, and A Rogers. Global habitat suitability of cold water octocorals. Journal of Biogeography 2012; 39(7):1278-1292.

[45] Rengstorf AM, Grehan A, Yesson C, Brown C. Towards High-Resolution Habitat Suitability Modeling of Vulnerable Marine Ecosystems in the Deep-Sea: Resolving Terrain Attribute Dependencies. Marine Geodesy 2012;35(4):343-361.

[46] Ross RE, Howell KL. Use of predictive habitat modelling to assess the distribution and extent of the current protection of 'listed' deep-sea habitats. Diversity and Distributions 2013;19(4):433-445.

[47] Field SA, Tyre AJ, Jonzén N, Rhodes J R, \& Possingham HP. Minimizing the cost of environmental management decisions by optimizing statistical thresholds. Ecology Letters 2004, 7: 669-675.

[48] Penney A. Mapping of High Seas Bottom Fishing Effort Data: Purposes, Problems and Proposals, SPRFMO Scientific Working Group document, 2010; SWG-10-DW-02 Rev1 <http://www.southpacificrfmo.org/assets/10thSWG-and-9th-DIWG-meetings-Vanuatu/SWG-10/Deepwater-Subgroup/SWG-10-DW-02-Rev1-Penney-2011-Highseas-bottom-fishing-effort-mapping.pdf> [Accessed June 2013].

[49] Weaver PPE, Benn A, Arana PM, Ardron JA, Bailey DM, Baker K, Billett DSM, Clark MR, Davies AJ, Durán Muñoz P, Fuller SD, Gianni M, Grehan AJ, Guinotte J, Kenny A, Koslow JA, Morato T, Penney AJ, Perez JAA, Priede IG, Rogers AD, Santos RS, Watling L. The Impact of Deep-Sea Fisheries and Implementation of the UNGA Resolutions 61/105 and 64/72: Report of a scientific workshop. National Oceanography Centre, Southampton, 2011. <http://hdl.handle.net/10013/epic.37995> [Accessed June 2013]. [50] <http://mgel.env.duke.edu/mget> [Accessed June 2013].

[51] Dunn DC, Boustany AM, Roberts JJ, Brazer E, Sanderson M, Gardner B, Halpin PN. Empirical move-on rules to inform fishing strategies: a New England case study. Fish and Fisheries 2013; n/a-n/a. doi:10.1111/faf.12019 [52] Sharp BR, Parker SJ and Smith N. An impact assessment framework for bottom fishing methods in the CAMLR Convention Area. CCAMLR Science 2009;16:195-210.

[53] Penney A, Guinotte J. Evaluation of New Zealand's high-seas bottom trawl closures using predictive habitat models and quantitative risk assessment. In press, PLOS ONE.

[54] Clark MR, Tittensor DP. An index to assess the risk to stony corals from bottom trawling on seamounts. Marine Ecology 2010; 31(suppl 1): 200-211.

[55] Sharp BR, Watters, GM. Marine Protected Area planning by New Zealand and the United States in the Ross Sea region. 2011. (Note: CCAMLR has not yet completed its planning of Ross Sea closures / MPAs.) 
[56] Poulsen RT, Cooper AB, Holm P, MacKenzie BR. An abundance estimate of ling (Molva molva) and cod (Gadus morhua) in the Skagerrak and the northeastern North Sea, 1872. Fisheries Research 2007;87:196-207.

[57] Myers RA, Hutchings JA, Barrowman NJ. Why do fish stocks collapse? The example of cod in Atlantic Canada. Ecological Applications 1997; 7:91-106.

[58] Clark MR, Vinnichenko VI, Gordon JDM, Beck-Bulat GZ, Kukharev NN, Kakora AF. Large scale distant water trawl fisheries on seamounts. Chapter 17. p. 361-399. In: Pitcher, T.J., Morato, T., Hart, P.J.B., Clark, M.R., Haggan, N. Santos, R.S. (eds). Seamounts: ecology, fisheries, and conservation. 2007. Blackwell Fisheries and Aquatic Resources Series 12 Blackwell Publishing, Oxford.

[59] Brander K. Global Fish Production and Climate Change. Proceedings of the National Academy of Sciences 2007; 104:19709-19714.

[60] Personal observation of one of the authors (AP). During a 2011 CCAMLR process to develop and evaluate alternative spatial closure proposals with all CCAMLR stakeholders, the fishing industry did, in fact, choose historical fishing effort as the best measure of cost of alternative spatial closures to them.

[61] Spatial Conservation Prioritization: Quantitative methods and computational tools. Moilanen A, Wilson KA, Possingham HP, Eds. Oxford: Oxford University Press, 2009.

[62] Ferrier S, Wintle BA. Quantitative Approaches to Spatial Conservation Prioritization: Matching the Solution to the Need. Ibid, Ch. 1.

[63] <http://www.uq.edu.au/marxan/> [Accessed June 2013].

[64] <http://cbig.it.helsinki.fi/software/zonation/> [Accessed June 2013].

[65] <http://uts.cc.utexas.edu/ consbio/Cons/consnet_home.html $\geq$ [Accessed June 2013].

[66] Klein C.J, Steinback C, Scholz A, Possingham H. Effectiveness of marine reserve networks in representing biodiversity and minimizing impact to fishermen: a comparison of two approaches used in California. Conservation Letters 2008; 1:44-51.

[67] Sharp BR, Watters, GM. Marine Protected Area planning by New Zealand and the United States in the Ross Sea region. CCAMLR 2011; WS-MPA-11/25.

[68] Clark MR, Dunn MR. Spatial management of deep-sea seamount fisheries: balancing exploitation and habitat conservation. Environmental Conservation 2012;39(3):204-214.

[69] Pomeroy, R., Douvere, F. The engagement of stakeholders in the marine spatial planning process. Marine Policy 2008; 32:816-822.

[70] Margules CR, Pressey RL. Systematic conservation planning. Nature 2000;405:243-253.

[71] Rice J \& Houston K. Representativity and networks of Marine Protected Areas. Aquatic Conserv: Mar. Freshw. Ecosyst. 2011; 21:649-657.

[72] International Seabed Authority. Decision of the Council of the International Seabed Authority relating to an environmental management plan for the Clarion Clipperton Zone. 2011; ISBA/17/C/19.

<http://www.isa.org.jm/files/documents/EN/17Sess/Council/ISBA-17C-19.pdf> [Accessed June 2013]. 